\title{
Crime scene to court: a study on finger-mark aging
}

\begin{abstract}
Fingerprint evidence is at the forefront of most criminal cases, with important issues raised regarding the age of the mark. Was the finger-mark deposited during the crime, or at a time not related for legitimate reasons? An in-depth understanding of their change over time from the initial to the aged stage, is paramount to applying a robust aging model. Focusing on the influential factors, including donor variability and environmental conditions, along with their effects on physical or chemical characteristics as aging parameters, previously proposed techniques have been analysed in attempt to find suitable parameters to solve the dating issue. This review suggests that despite the variation of methods trialled, the question of fingermark dating remains largely unanswered. Whilst some techniques showed promise, they all possessed limitations, mainly due to the large effects of influential factors inconsistently altering the deposit over time. Without reproducible aging trends, estimating an accurate and reliable age is unrealistic. Considering additional research, there is requirement for an aging method to be tested using large donor volumes and contaminants on a wide range of substrates. Each must be subjected to ranging environmental conditions to plot aging curves. Reviewing and comparing the techniques, benefits have been identified for selecting target lipid compounds and obtaining ratios between them. Proposing a spectroscopic method, coupled with an analytical instrument enables for quantification to observe a model for application to a multitude of scenarios. In the ideal situation, the method should be validated and undertaken in an accredited laboratory, meaning results obtained would stand up to cross- examination when employed in court.
\end{abstract}

Keywords: finger-mark, aging, initial composition, aged composition, physical, chemical, influential factors

\section{Introduction}

Fingerprints provide vital evidence at the crime scene, enabling experts to analyse and identify the unique network of ridges making up the mark. As primary evidence in criminal investigations, fingerprints are the most frequently used, being presented as evidence five times more often than DNA, ${ }^{1}$ indicating the valuable strength and reliability. However, all evidence in court is open to challenge, raising questions regarding when the mark was deposited. The ability to provide the deposition age would have a significant impact on the relevance of the mark and the outcome of the case. There is distinct lack of research and knowledge in relation to the time between deposition and recovery of finger-marks, ${ }^{2,3}$ establishing the requirement for sound scientific knowledge that could provide accurate aging of finger-marks for investigative and court purposes. This is extremely important in the criminal justice system, when, professional knowledge and experience must be based on scientific methodologies demonstrating robust, accurate reproducibility to add weighted evidence in court, as monitored by the United Kingdom Accreditation Service. ${ }^{4}$ Focusing on ways in which finger-marks can be analysed to indicate how long the mark has been present adds strong evidence, minimising wrongful convictions. This review provides a brief background of fingerprints and their use in the criminal justice system, utilising and assessing existing research on the initial and aged finger-mark composition, ${ }^{5}$ exploring the effects of variables; including environmental influences and donor characteristics, whilst evaluating techniques used to age the ridge detail and testing reliability. Using knowledge, figures and literature of the chemical composition of finger-marks, techniques and the effect of time, focussing on investigative, physical and chemical processes to make an assessment and determine if, the aging of fingermarks could be used in court. Previously proposed methods for fingermark dating will be reviewed, displaying understanding of advantages
Volume 6 Issue 6 - 2018

\author{
Andrew O Hagan,' Sophie Green² \\ 'Andrew $O$ Hagan, Department of Science and Technology \\ Nottingham Trent University, UK \\ ${ }^{2}$ Sophie Green, Department of Science and Technology \\ Nottingham Trent University, UK
}

Correspondence: Andrew $\bigcirc$ Hagan, Department of Science and Technology Nottingham Trent University, Clifton Lane, Nottingham NGI I 8NS United Kingdom, Tel +44I I 58483 I53, Email andrew.ohagan@ntu.ac.uk

Received: November 05, 2018 | Published: December 07, 2018

and disadvantages of each procedure. A reliable method to provide quantitative values would be extremely advantageous in court, providing conclusive evidence tested beyond all reasonable doubt.

\section{Discussion}

\section{Background of fingerprints}

Friction ridge skin patterns can be found on palms, hands and feet, forming complex designs ${ }^{6}$ which can be easily identifiable. It is widely known that no two fingerprints are identical ${ }^{7}$ the probability of two fingerprints being the same being 64 billion to $1^{6}$ Indicating their importance for 100 years $^{8}$ with all patterns remaining the same through a lifetime even after injury (Figure 1). ${ }^{9}$

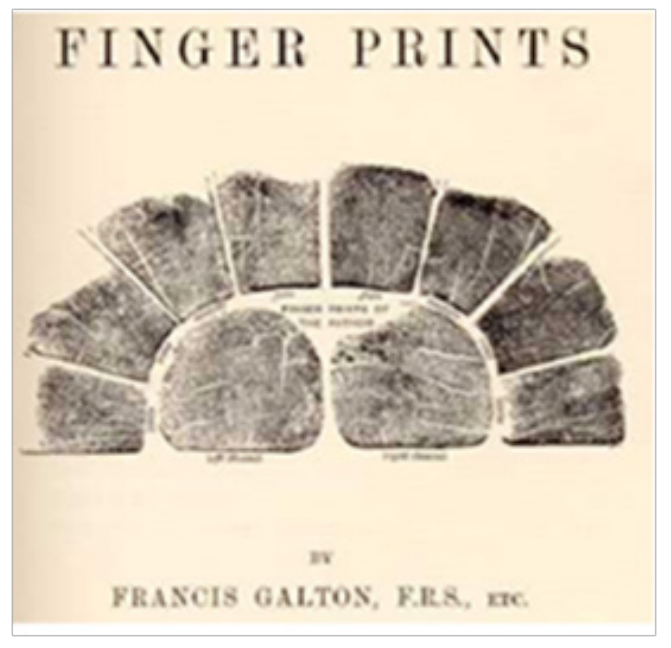

Figure 1 'Finger Prints' publication by Sir Francis Galton.? 
Locard's exchange principle states every contact leaves a trace. ${ }^{10}$ Perspiration secretes pores as friction ridge aligned in single rows. Secretions are transferred through contact producing an impression of the ridge pattern. ${ }^{11}$ These consist of components from the epidermis, secretary glands, with components such as traces of drugs and other contaminants, including blood and cosmetics. ${ }^{2}$ Both intrinsic and extrinsic contaminants vary substantially between individuals, exhibiting intervariable signs varying on individuals over time, known as intravariability. ${ }^{2}$ More research is needed to investigate the effect on the aging process.

\section{Finger-mark composition}

\section{Initial and aged}

Quantitative analysis for age determination requires understanding of finger-mark composition and aging. The composition complex, possessing high levels of donor variability and contaminants, degrading over time from the initial to the aged composition. ${ }^{5}$ A mark will never be recovered from a scene immediately, considerable time elapses, biological, chemical and physical factors influence the mark altering the composition. ${ }^{5}$ Consequently, when investigating residue, initial composition and aging together with influential factors must be considered.

\section{Initial composition}

Research has attempted to qualitatively and quantitatively analyse finger-mark residue, challenges due to the low total mass and low concentrations of components cause detectability issues. ${ }^{12}$ Fingermark residue is described as a complex system which evolves over time ${ }^{5}$ demonstrating the difficulty in analytically quantifying changing. See Figure 2 for visual representation.

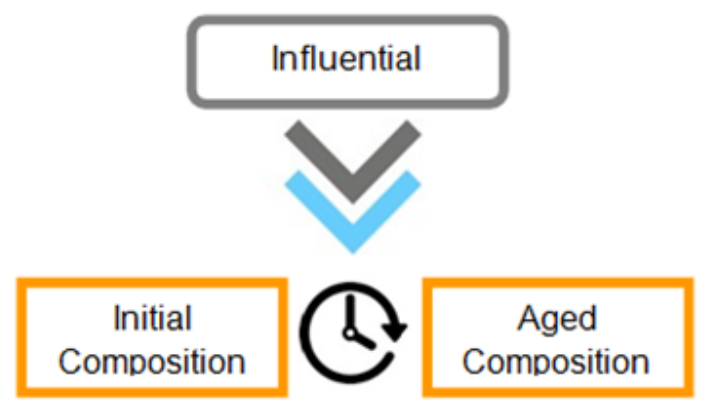

Figure 2 A graphic representation of how finger-mark composition alters over time from the initial to aged composition whilst being influenced by various factors. ${ }^{5}$

Finger-mark residue consists of eccrine, apocrine, sebaceous and epidermis secretions and extrinsic contaminants. ${ }^{5,13}$ Figure 3 displays gland locations in non-friction ridge skin. ${ }^{14}$ Eccrine sweat is secreted from glands located all over the body and is thought to possess a composition of $98 \%$ water, with organic and inorganic components. ${ }^{2,13}$ However, evidence supports that latent finger-marks have only $20 \%$ water immediately after deposition. ${ }^{12}$ This could alter results significantly. Studies identify twenty amino acids in the eccrine component ${ }^{15}$ along with inorganic compounds including chloride, potassium and calcium. Apocrine sweat has minor contribution to finger-mark residue, however is more significant in cases of a sexual nature, with glands located in the groin and underarms (Figure 3). ${ }^{5,16}$

Sebaceous glands found all over the body except for the hands and feet, ${ }^{5}$ contributing to finger-mark residue resultants in transfer onto the fingers via contact with other bodily areas. Sebaceous sweat (sebum) is composed of numerous organic compounds, mostly lipids, including fatty acids and triglycerides which make up 57.5\%, long chain fatty esters contributing $26 \%$, squalene-a linear intermediate compound which precedes cholesterol, makes up $12 \%$, and finally sterols e.g. cholesterol and its esters account for $4.5 \% .{ }^{17}$ Contaminants also contribute and can include cosmetics and foodstuffs. ${ }^{13}$ These contaminants may cause confusion and difficulty in differentiating from the intrinsic secretions due to the similar lipid compounds. The initial composition of finger-mark residue varies significantly between individuals and the same individual due to several known and unknown influential factors-see Table 1. These require thorough evaluation as they form an important part of any proposed methodology for providing finger-mark age estimations.,5 Each variable has considerable effect on the deposition/initial composition. The significant aspects are visually represented in Figure $4 \&$ Table $1 .{ }^{2}$

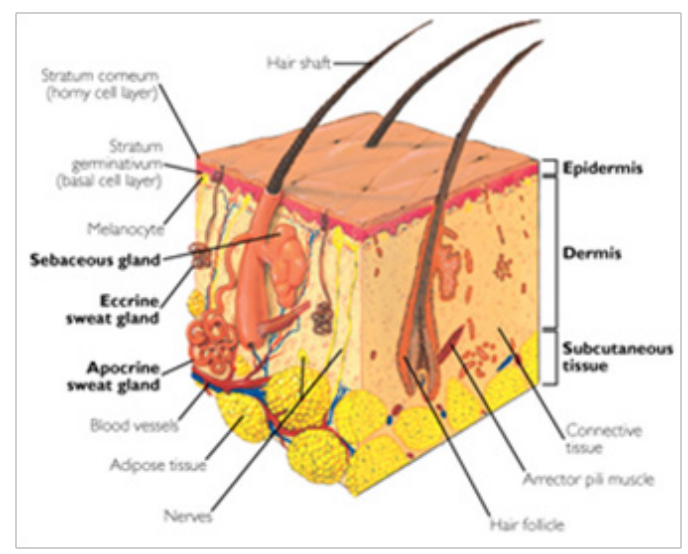

Figure 3 A visual representations of gland locations under the skin. ${ }^{14}$

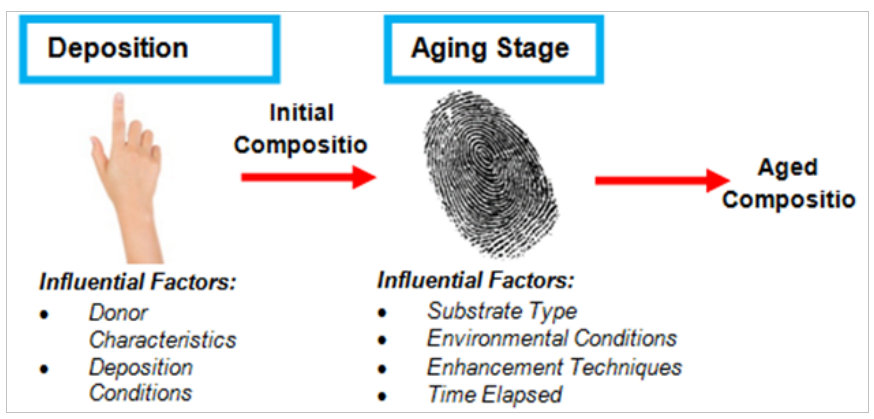

Figure 4 Influential factors affecting the deposition and aging stages of fingermark residue. ${ }^{2}$

Table 1 Influential factors affecting the deposition stage of finger-mark residue ${ }^{2,5}$

\begin{tabular}{ll}
\hline Deposition stage & \\
\hline Influential factor category & Example \\
\hline Donor Characteristics & Gender, Age, Diet, Race \\
Deposition Conditions & Contact time, Angle, Pressure \\
Substrate Type & Porosity, Surface texture, Curvature \\
\hline
\end{tabular}

\section{Aged composition}

From the moment of residue deposition, further aspects affect the composition. These cause degradation of the constituents, resulting in aged residue..$^{2,5}$ The influential factors are seen in Figure 4 \& Table 2. 
Table 2 Influential factors affecting the aging stage of finger-mark residue ${ }^{2,5}$

\begin{tabular}{ll}
\hline $\begin{array}{l}\text { Aging stage } \\
\text { Influential factor category }\end{array}$ & Example \\
\hline Substrate Type & Porosity, Surface Texture, Curvature \\
Environmental Conditions & Temperature, Light/darkness, Humidity \\
Ridge Detail Enhancement & $\begin{array}{l}\text { Methods which alter chemical/physical } \\
\text { Techniques }\end{array}$ \\
Time Elapsed Between & Longer time, more degradation \\
Deposition and Analysis &
\end{tabular}

The variable nature of initial and aged composition indicates that methodology to accurately identify characteristics would require extensive planning and control over all but one of the variables separating the effect of individual factors on the composition. Donors are difficult to find who repeatedly deposit residue of an identical nature due to intravariability. ${ }^{2}$ After deposition, the aging process involves degradation and drying out of the residue. This can result in the mark appearing duller, the ridges narrowing and the increasing loss of continuity of ridge flow. ${ }^{18}$ CAST (The Centre for Applied Science and Technology), ${ }^{19}$ understand that when investigating eccrine components, the finger-mark will dry out over a short time due to the high-water content $(98 \%)$ evaporating. ${ }^{2}$ The residue could therefore experience a decrease of up to $98 \%$ of its original mass within just 72 hours of deposition. ${ }^{20}$ Leaving organic compound. amino acids, and inorganic salts as the main constituents. Organic compounds may only degrade after much longer time. Inorganic salts demonstrate much higher stability and will remain longer still, unless exposed to moisture. ${ }^{19}$ Sebaceous components of print residue are similar to eccrine. ${ }^{19}$ Constituents such as Squalene, degrade and are lost over time $^{13,21}$ unlike others remaining for years. This is supported by a report, ${ }^{22}$ whereby TLC was used to investigate lipids in mark residue. Visualisation of the residue from fresh marks and older marks showed considerable difference. When test latent prints were placed in a $90^{\circ}$ oven for aging periods of 30 minutes to 4 hours, lipids disappeared from the residue in the sequence;

I. Free fatty acids

II. Cholesterol

\section{Squalene}

Triglycerides and wax esters were visible in all samples, showing that despite only aging for a maximum of 4 hours, the lipids were lost rapidly. The loss may have been sped up due to the high temperature, but this influential factor requires additional investigation. Organic components have shown to be reasonably stable after deposition but will degrade over time. ${ }^{19}$ Contaminants are contributory factors in finger-mark residue, understanding how they survive/degrade with time is crucial. Considering blood contaminant, water components evaporate over hours/days, drying out the mark..$^{19}$ Leaving proteins which persist over years eventually degrading. Contaminants such as grease will generally dry out and display progressive degradation. ${ }^{19}$ Understanding the capabilities of fingerprint enhancement treatments, visualisation of changes in aging finger-mark residue is possible. Physical Developer is an enhancement process used on porous items like paper, to detect latent finger-marks by forming silver/grey deposits on the ridges. ${ }^{23}$ The aqueous, silver-based reagent ${ }^{24}$ relies on the interaction of colloidal silver particulates with the lipids and fatty acid constituents of the sweat residue..$^{23}$ It is thought that PD targets eccrine constituents trapped within a water-insoluble matrix, ${ }^{19}$ $\mathrm{PD}$ is ideal for enhancements on wet porous items indicating an age of finger-marks and is more successful on older marks. The desired constituents for the reaction persist for much longer than those, like amino acid components, possibly due to a protective layer formed around the lipids and fatty acids of interest when the finger-mark dries out. ${ }^{19}$

\section{Age determination}

Uncertainty in the scientific ability to determine an exact age of finger-marks is reported answers being provided by expert witnesses in court. In some cases experiments supported answers, some based on guesswork and personal experience. Opinions have been offered on the age of finger-marks by estimating the 'apparent freshness' and therefore time since deposition. Assumptions were made that on external surfaces, environmental conditions and weather will fade, damage and destroy marks progressively ${ }^{25}$ However, as seen in an Australian case, ${ }^{5}$ described below, this assumption is generalised and not always true. Describing a mark as looking 'fresh' to designate an age/time frame will not suffice. Figure 5 demonstrates that visually, the quality of a mark after powdering is not enough to assume the age; more reliable parameters are a necessity. ${ }^{25}$
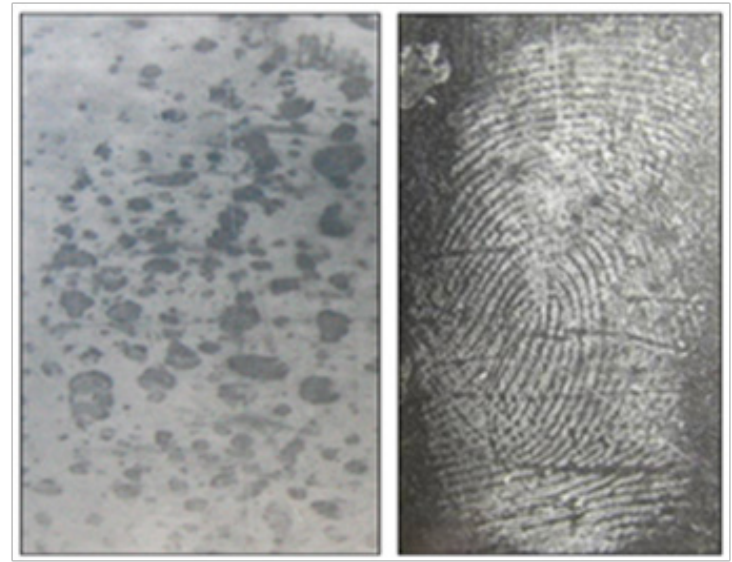

Figure 5 Left image to show a 20-day old finger-mark in Coca-cola contaminant on an external uPVC surface, compared with the right image which shows a finger-mark aged over I year, deposited in the oil contaminants from sausage and chips on a glass substrate stored outside and exposed to weather conditions. ${ }^{25}$

This displays that contaminant plays an important role in the persistence of a finger-mark and therefore it is unreliable to assess a mark as fresh unless the contaminant and chemical composition have been thoroughly analysed.

\section{Finger-mark dating techniques}

Research conducted provides accurate answers for age ${ }^{2-26}$ Similarities between methods suggest they have focussed on three areas of research; investigative information, observed visual changes in the physical characteristics and degradation/aging of chemical characteristics in the residue ${ }^{2}$ often choosing a specific target compound to analyse changes.

\section{Investigative methods}

Investigative information demonstrates the importance of not drawing conclusions based on the visible quality of the ridges. A case 
is described in Australia, whereby high-quality ridge detail was found at a crime scene on an external window. ${ }^{5}$ The mark was identified to a police officer, adamant he had not been at that location for 2 years prior when attending a previous crime. However, expert fingerprint officers were convinced the ridge detail was fresh due to the good quality considering the external surface exposed to the elements. It wasn't until other areas of detail of consistent quality on this window were identified to another officer that investigators understood the identified officers hadn't worked together since last attending the premises 2 years before. This proved that despite the exceptional quality of finger-marks on the external window appearing fresh; they were in-fact 2 years old, further solidifying that conclusions cannot be drawn by looking at the quality alone. Work has been conducted to investigate how long a finger-mark may persist on glass exposed to a range of weather conditions (heavy snowfall, rain, strong winds and sunshine. ${ }^{25}$ It focussed on persistence using 7 different contaminants, with preliminary studies confirming eccrine, sebaceous and apocrine would not persist. Persistence was investigated over 3 -month, 1 year and $2 \frac{1}{2}$ year time periods to track aging and if marks would disappear as initially expected. Looking below Figure 6, from the initial 7 contaminants used, some marks did not persist, however there were a number, especially ones deposited in the oil from sausage and chips and linseed oil putty that persisted to a high quality, with aluminium powder effectively enhancing them.

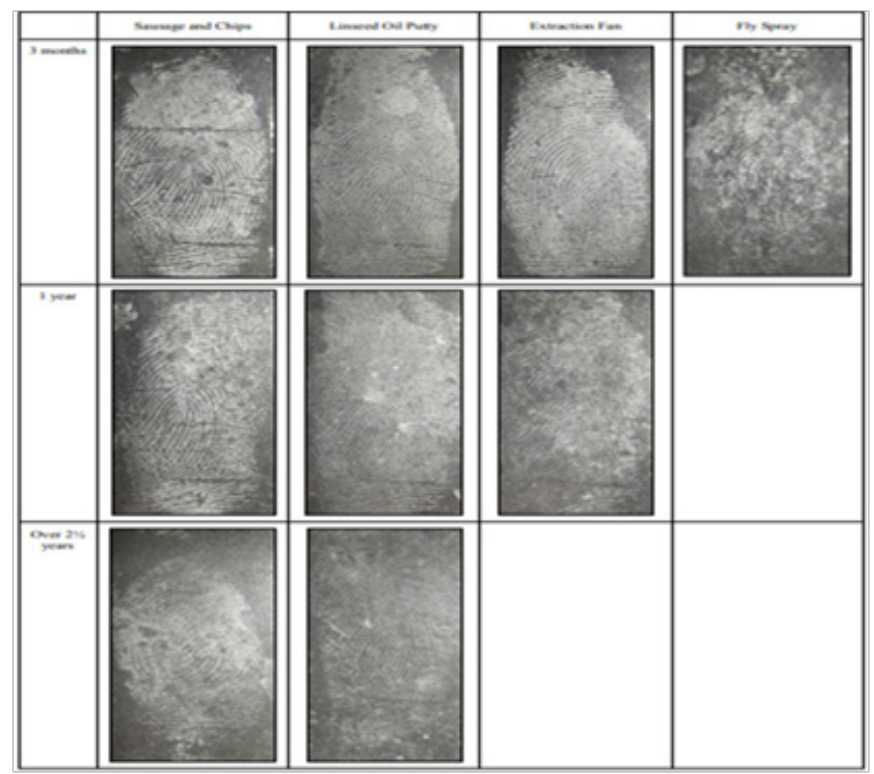

Figure 6 Images of finger-mark persistence of up to and over 2 I/2 years using oil from sausage and chips, linseed oil putty, grease from an extraction fan and fly spray as deposition contaminant. ${ }^{25}$

These results proved that it was unsuitable for the expert in Australia $^{5}$ to assume that the finger-mark on the external window could not have survived to high-quality standard for 2 years. The research ${ }^{25}$ provides visually compelling data, but it must be considered that only 1 donor was used, raising questions regarding the reliability, considering intervariability. Different donors could react differently to result in other contrasting contaminants displaying a more successful persistence. It gives rise to requirement for parameters capable of measuring the change in quality over time whilst knowing the contaminant and potentially the initial composition. Gathering all information prior to drawing conclusions is paramount for ensuring evidence is correct. Understanding the environment and circumstances, determination of when a finger-mark was deposited may be possible. For example, if a burglary occurred in a jewellery shop and a suspect-identified latent finger-mark was recovered from a glass cabinet which contained the stolen jewellery, with potential intelligence from staff that the cabinet was thoroughly cleaned in the day time prior to the evening burglary, it may be wise to conclude that the finger-mark in question was not left prior to the surface being cleaned. Therefore, a suspect's account of their fingerprints being deposited legitimately when previously visiting the shop could be discounted by providing the evidence that the mark was left after the cabinet had been cleaned. However, this lacks scientific proof that may result in evidence questioning. Additional investigation such as CCTV evidence could confirm aging by seeing where the suspect's hands were placed on the counter during the burglary.

\section{Changes in physical characteristics}

Research for dating fingerprints using their physical characteristics; focus largely on the ridges and microscopic properties as aging parameters. This involves analysis of third level Galton details including edgeoscopy and poroscopy (the shape of ridges and sweat pores). ${ }^{7,26}$ Discussed below are techniques that have aimed to assess changes within ridges and pores to apply an aging model. Despite drawbacks, visible aging patterns were observed and measured.

\section{Morphology, structure and biochemical characteristics}

Over a two-year period in Romania $^{27}$ research investigated morphological, structural and micro/macroscopic and biochemical characteristics of ridge detail to propose finger-mark age estimations. Table 3 shows areas of investigation interest.

Table 3 A summary of study objectives used in Romania to estimate fingermark age $\mathrm{e}^{34}$

\begin{tabular}{ll}
\hline Objectives of Study & \\
\hline Physical characteristics & Biochemical characteristics \\
\hline$\cdot$ Ridge thickness & $\cdot$ Quantifying total DNA \\
$\cdot$ Distance between valleys/ridges & $\begin{array}{l}\text { Quantifying degradation from } \\
\text { different blood groups }\end{array}$
\end{tabular}

Quantity of minutiae

- Quantity of pores

Quantity of epithelial cells

Over 800 fingerprints were used for this study but donors possessed limited variability by undertaking similar daily tasks. It would be more beneficial to obtain donors from all backgrounds to grasp the effects of intervariability factors on a more widespread basis. Microscopic analysis established the shape and location of the pores. It was described that immediately after deposition, the pores were near each other, located either centrally or towards the edges of the ridges. Pores in the centre were well defined and closed, unlike those at the periphery that were open or closed. Further analysis after 5 days determined that the pore shapes had altered, with some opening. It was observed that with ridge degradation, some pores disappeared altogether. Remaining pores appeared to get closer and began joining into chainlike formations. Despite these significant findings, the aging period was only 5 days and therefore cannot provide an accurate representation of how degradation impacts pores over longer, 
more realistic time periods. If pores disappeared after only 5 days, complete disappearance is possible by analysis time and therefore as an aging parameter they are unrealistic. Additionally, varying deposition conditions could mean that not all pores are transferred across on to the questioned mark or 10 print identification form, potentially leading to confusion when observing corresponding pores. A consistent time period was employed for measurement of ridge thickness and valley width, ensuring that readings were taken every 15 days for 180 days. This larger time period better replicates forensic time frames, providing more reliable data. Different influential factors were considered, storing samples indoors and outdoors to understand the impacts. Table 4 shows the measurements obtained and Figure 7 provides visual representation of ridges and pores changing with time when viewed macroscopically.

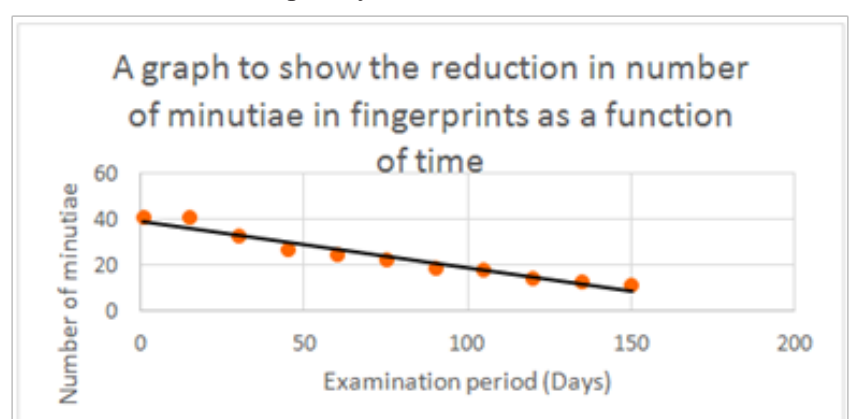

Figure 7 A graphical representation of table 3, showing that a straight-line plot can be produced for the disappearance of minutiae in a finger-mark over 150 days. $^{34}$

Table 4 Results for measurements of ridge thickness and valley width over a period of 180 days $^{34}$

\begin{tabular}{lllll}
\hline Storage & \multicolumn{2}{l}{ Ridge thickness } & Valley width & \\
\hline & Day 1(mm) & Day 180(mm) & Day 1(mm) & Day 180(mm) \\
\hline Indoor & $0.30-0.34$ & $0.24-0.28$ & $0.24-0.28$ & $0.28-0.30$ \\
Outdoor & $0.28-0.32$ & $0.22-0.26$ & $0.26-0.28$ & $0.26-0.28$ \\
\hline
\end{tabular}

Evaluating the results in Table $4,{ }^{27}$ the environmental conditions appear to slightly affect the ridge thickness. Those indoors generally had thicker ridges than those outdoors as replicated from day 1 through 180. However, as measurements from the different environments overlap, it cannot be said that the difference observed is statistically significant. Looking at the difference from day 1-180, there is an obvious correlation that ridge thickness diminished over time. An explanation being the mark undergoing degradation and drying out, with heavier mass constituents evaporating and leaving the ridges. ${ }^{18,19}$ In contrast to the ridges, the valleys display an increasing width over time when stored indoors. With decreasing ridge width, the gaps (valleys) between them will increase. The data overlaps however, meaning no statistical significance. Analysing the outdoor stored ridges, a difference is not seen in valley width over the measured time. This would suggest valley width is unsuitable as an aging parameter as no aging characteristics were identified. The ridge thickness and valley width appear to possess other useful evidential value, with studies suggesting males generally possess thicker ridges, whilst females commonly have a higher ridge density ${ }^{28,29}$ Using minutiae as an aging parameter, results Table 5 suggested an aging curve could be plotted using number of minutiae at consistent time intervals (Figure 7). ${ }^{27}$ Minutiae are described as ridge discontinuities, where a ridge may end (ridge ending) or split in two (bifurcation). ${ }^{30}$
Table $5 \mathrm{~A}$ table showing the results obtained for the reduction of minutiae with time ${ }^{34}$

\begin{tabular}{ll}
\hline Examination period (Days) & Number of minutiae \\
\hline 1 & 41 \\
15 & 41 \\
30 & 33 \\
45 & 27 \\
60 & 25 \\
75 & 23 \\
90 & 19 \\
105 & 18 \\
120 & 15 \\
135 & 13 \\
150 & 12 \\
\hline
\end{tabular}

A clear trend in reduction of minutiae with time is displayed, ${ }^{27}$ providing significant potential for age determination. Despite this observation, along with the changing ridge/valley widths, there are considerable limitations in applying this in the field. A crime scene finger-mark will only provide information of the mark appearance at the specific moment in time (i.e. recovery or examination). During analysis, only the number of minutiae present at that point is shown and therefore without a way to replicate storage, environmental and deposition factors exactly, tracing back in time to the original appearance presents difficulty. Obtaining a known mark from the suspect under 'known' conditions and replicating circumstances in the time since deposition, comparisons may be drawn to present a case specific aging model. Utilising the physical characteristics and morphology relies less on chemical reactions of finger-mark residue, so ultimately may suffer from less contamination issues and provide higher success rates (Figure 8).

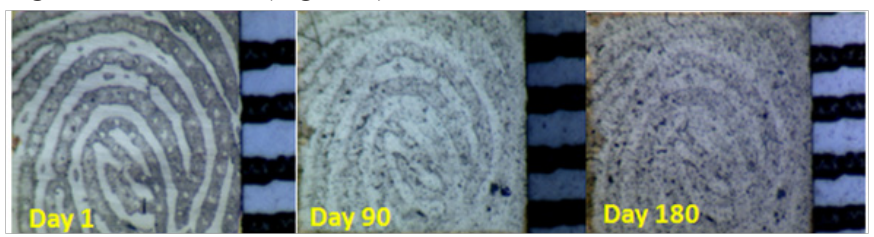

Figure 8 Macroscopic images showing the effect of aging on a finger-mark after initial deposition, 90 days and 180 days. ${ }^{34}$

Additional work in Romania concluded that the blood group of an individual may directly impact finger-mark degradation. ${ }^{27}$ This introduces a new influential factor, falling under the 'donor' category which may require further research to establish its true effects on aging, alongside other variables.

\section{Electrostatic charge}

One study focused imaging the electrical charge of finger-mark residue, using an electric field microscopy system as an aging parameter. The scanning probe revealed latent electric finger-mark impressions resulting from finger contact with a surface due to an impression of charge. The charge impression was of sufficient quality for identification of the finger-mark, due to exceptionally high sensitivity and low noise levels. A limitation of the method is its unsuitability for use on very old fingerprints as the ridges are not 
visible with charge imaging. More recent/fresh finger-marks have displayed much more potential. A clear exponential decay curve was obtained to display charge reduction with time. Despite promising outcomes, limitations were revealed. These primarily focused on the substrate with the rate of decay showing dependency. Additionally, only plastic substrates were investigated-not representative of live casework. Environmental factors also significantly affected decay rate, but opposing this, the technique demonstrated success in providing the first stages of an aging model, noticing the possibility to trace time using the decay of charge. A benefit of this procedure is the non-destructive nature, meaning the finger-mark patterns and residue remains intact, unlike methods requiring dissolution and destruction of the mark to produce a liquid matrix. Future prospects consist of portable instruments capable of scene use, enabling shorter scan times and quicker results. Furthermore, prior to method validation or field use, more research should be undertaken to include more donors with a variety of contaminants and varied initial residue composition (i.e. eccrine or sebaceous). This offers a positive outlook for developments using electric charge of finger-mark deposits to aid with age determination.

\section{Age determination from a policing perspective}

Lack of research into age determination by police staff is noticeable, but literature describes investigations using fingerprint experts and live casework to draw conclusions on visual degradation. ${ }^{32,33}$ It is explained how the visual examination of finger-marks deposited on smooth, non-porous surfaces (glass, metal and plastic) was conducted over a period of one day to several years. ${ }^{32-34}$ Observations included marks fading and drying, along with the loss of adhesive properties and ridge thickness decreasing with time. ${ }^{33,34}$ Influential factors (i.e. temperature, dust concentration and humidity) were considered and conclusions supported the theory that finger-marks persisted longer on glass. Marks on plastic had been observed with shorter persistence due to the surface electrostatic charge which consistently attracted dust. ${ }^{18}$ Without a specific aging model, Holyst's research appears to rely on subjective examination alone and therefore lacks accuracy and reliability. This method was implemented in the 1970s as an age determination approach for the Dactyloscopy Department for the Main Police of Warsaw. ${ }^{18-34}$ It revolved around the visual examination of around 20,000 fingerprints from crime scene reconstructions to control environmental conditions. The employed technique used only smooth, non-porous surfaces, perhaps one of the largest limitations. When a suspect was identified from a scene mark, they would deposit sample marks on reconstructed surfaces/scenes which were subsequently lifted at various aging stages. A video comparator enabled fingerprint experts to analyse and compare the initial mark with the aged 'test' mark and visualise degradation. Relying on an expert's interpretation means subjective conclusions, introducing potential for error and disagreement. A database was utilised by the experts, containing useful information including components of finger-mark residue and environmental conditions of the initial crime scene. Experts had given evidence based on this study and in $88 \%$ of these hearings, suspect statements regarding time frames at scenes were rejected. ${ }^{33,34}$ It uncertain how much validity can be placed on this study, considering the subjective nature. An advantage, in contrast to other studies is the vast number of finger-marks examined. Additionally, intelligence gathered from live scenes enabled conditions to be replicated to a reasonable extent. However, as with many other research studies, it appears to have neglected some vital influential factors (i.e. intravariability from initial residue composition, donor characteristics and contaminants), resulting in questions arising in the integrity and if the model was reliable to deal with live convictions.

\section{Comparison of methods utilising physical characteristics}

(Table 6)

Table 6 A table to show comparison with the advantages and disadvantages of each of the physical characteristic techniques used in attempt to estimate the age of a finger-mark

\begin{tabular}{|c|c|c|}
\hline Technique & Advantages & Disadvantages \\
\hline $\begin{array}{l}\text { Microscopic } \\
\text { Analysis } \\
\text {-Poroscopy }\end{array}$ & $\begin{array}{l}\text {-Less contamination than chemical processes } \\
\text {-Non-destructive }\end{array}$ & $\begin{array}{l}\text {-Limited donor variability } \\
\text {-Unrealistic aging period ( } 5 \text { days) }\end{array}$ \\
\hline $\begin{array}{l}\text { Microscopic } \\
\text { Analysis } \\
\text {-Ridge Thickness } \\
\text { \& Valley Width }\end{array}$ & $\begin{array}{l}\text {-Realistic aging period ( } 180 \text { days) } \\
\text {-Indoor and outdoor conditions replicated } \\
\text {-Correlation observed of ridge thickness decreasing over time } \\
\text {-Less contamination than chemical processes } \\
\text {-Non-destructive }\end{array}$ & $\begin{array}{l}\text {-Ridge thickness/ valley width not likely known at } \\
\text { time of initial deposition at crime scene } \\
\text {-Valley width not suitable as no aging parameters } \\
\text { identified }\end{array}$ \\
\hline $\begin{array}{l}\text { Microscopic } \\
\text { Analysis } \\
\text {-Minutiae }\end{array}$ & $\begin{array}{l}\text {-Realistic aging period ( } 150 \text { days) } \\
\text {-An aging curve was plotted } \\
\text {-It has the possibility of creating a case specific aging model } \\
\text {-Less contamination than chemical processes } \\
\text {-Non-destructive }\end{array}$ & $\begin{array}{l}\text {-Difficult to trace back in time to identify the } \\
\text { condition of finger-mark at initial deposition }\end{array}$ \\
\hline $\begin{array}{l}\text { Electrostatic } \\
\text { Charge }\end{array}$ & $\begin{array}{l}\text {-Obtains an image suitable for identification of finger-mark } \\
\text {-An exponential decay curve was obtained } \\
\text {-High sensitivity and low noise, therefore reliable data outcome } \\
\text {-Non-destructive }\end{array}$ & $\begin{array}{l}\text {-Not suitable for very old fingerprints } \\
\text {-Rate of decay is extremely substrate dependent } \\
\text {-Limited donors, substrates and residue } \\
\text { contaminants }\end{array}$ \\
\hline $\begin{array}{l}\text { Visual } \\
\text { Comparison }\end{array}$ & $\begin{array}{l}\text {-Crime scene conditions were replicated } \\
\text {-Very large donor group used } \\
-88 \% \text { of hearings using this finger-mark dating technique were } \\
\text { successful at discrediting the suspects testimony } \\
\text {-Non-destructive }\end{array}$ & $\begin{array}{l}\text {-Subjective conclusions- not scientific } \\
\text {-Some influential characteristics not accounted for }\end{array}$ \\
\hline
\end{tabular}




\section{Changes in Chemical Characteristics}

Chemical components in finger-mark residue undergo changes over time by degradation..$^{2-22}$ Research has proposed that a practical way to quantify these changes is to determine a specific target compound present in the residue (ideally of everyone), for analysis to produce an aging curve. Ratios of target compounds have proved successful parameters, considering unknown initial values. Influential factors must be considered, presenting difficulty in controlling all but one factor each time. Below are several researched methods with their success and possibilities for the future. ${ }^{35}$

\section{Autofluorescence}

Fingerprints possess autofluorescence properties when excited by visible or UV light, which can be utilised for their detection. In 1980, Menzel ${ }^{36}$ investigated differences in the fluorescence of 'fresh' and 'old' marks and observed a red-shift in marks of varied ages. Unfortunately, relating to the initial variability of the fluorescence, quantification could not be achieved and therefore no aging model was produced. The components providing the autofluorescence were investigated using Thin Layer Chromatography (TLC) and fluorescence spectroscopy to understand the potential forensic value. ${ }^{37}$ By aiming to identify fluorophores (components which cause molecules to absorb and re-emit energy of different but specific wavelengths) $)^{32}$ fluorescence imaging was possible to gather donor information. Fingerprints were deposited onto TLC plates and fluorophores found in sweat, skin and sebum were used as reference compounds. An important finding during this experiment was that finger-marks deposited in a morning produced a more intense fluorescence emission than those in an afternoon. The suggestion of oxidative stress causing this requires further investigation. If reproducible data and knowledge of quantification possibilities was obtained, it could provide high evidential value in assigning a deposition time. Finger-mark residue mostly showed blue or yellow autofluorescence, sometimes combined with red/orange and it was hypothesized that the source was from protein bound tryptophan-a fluorescent amino acid found in large quantities in the body. The study suggests that it is only a major fluorescence contributor when part of a peptide or bound to a protein. Another important finding was that autofluorescence initially increased with time, as indicated by a tryptophan reference standard and that fluorescence was stronger on older marks than fresh deposits. As expected, different donor deposits displayed highly variable autofluorescence, with some not fluorescing at all, resulting in difficulty quantifying non-visible components. A more recent study focused on autofluorescence of aged finger-marks using previous knowledge of fluorescence changing with time. ${ }^{38}$ In 1992, Menzel explained that fresher finger-marks displayed yellow autofluorescence unlike older marks that were red. Understanding this, along with aging rates, Lambrechts ${ }^{38}$ demonstrated success in estimating finger-mark ages under controlled conditions with an accuracy of 1.9 days. As seen in the article, protein bound tryptophan was the main contributor of autofluorescence in fresh marks, but protein fluorescence decreased with time. Again, TLC was used but this time to separate out fluorophores at increasing time points after residue deposition. Fluorescence spectroscopy was then used for identification. Storage conditions were considered-some stored in a dark chamber and others open to an office environment for $0,1,2$ and 3 weeks to obtain aged compositions. Where the original article focused autofluorescence at $\mathrm{t}=0$, this one focused on $\mathrm{t}=0, \mathrm{t}=1, \mathrm{t}=2$ and $t=3$. Figure 9 shows fluorescence was much weaker for fresher marks. It was concluded that finger-marks stored in both the dark room and office environment showed extremely similar fluorescent spots, whereas the intensity was noticeably stronger when aged in the dark.

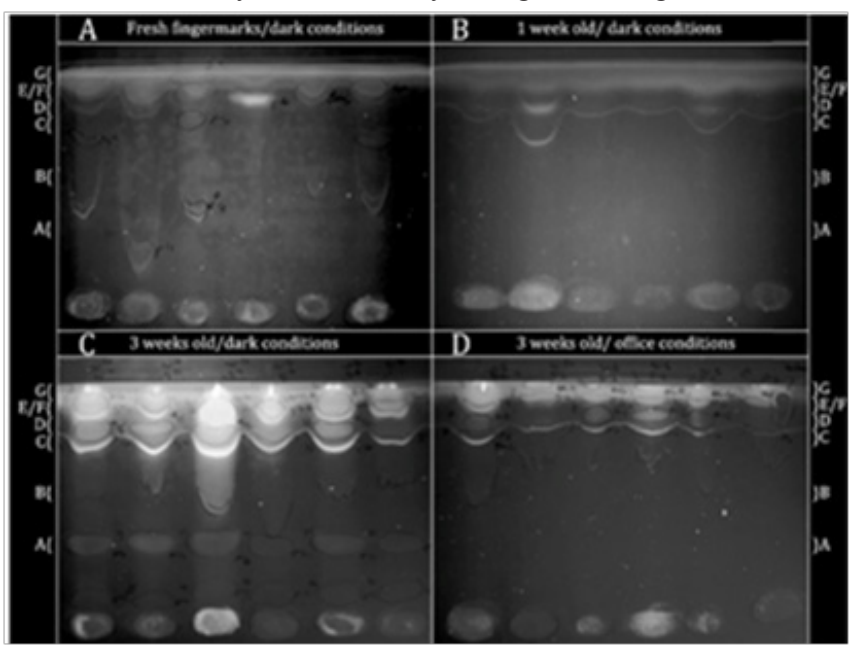

Figure 9 TLC plates stored in the dark and office environment, showing the auto fluorescence of finger-marks that change over time. ${ }^{27}$

Specific fluorescent spots were coloured by Ehrlich's reagent (Figure 10), indicating the similarities and differences between storage conditions. Tryptophan did not produce fluorescent spots when fresh but with aging, six spots were visible. Figure 11 displays the similarities of the tryptophan reference sample and spot D from the test residue on the excitation and emission spectra indicating the importance of tryptophan.

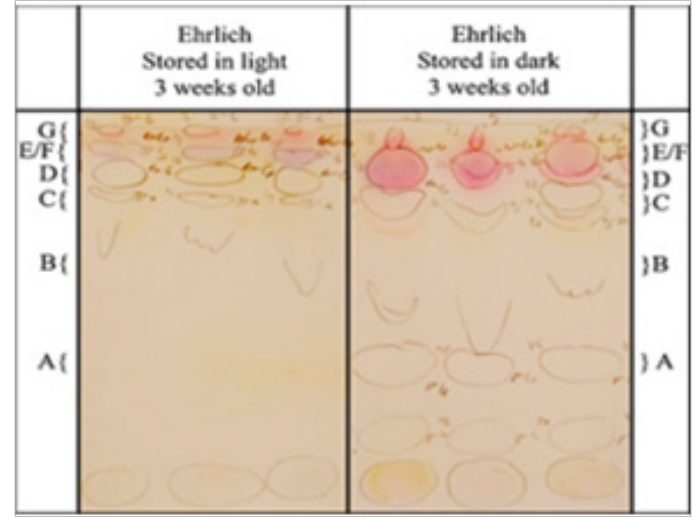

Figure 10 TLC plate showing the use of Erhlich's reagent to visually compare the autofluorescence of finger-marks when stored under different environmental conditions. ${ }^{27}$

Additional information gained, Figure 10 is that spot D (reference or test residue) did not react with Ehrlich's reagent, indicating that tryptophan derivatives play an important role in the autofluorescence of aged finger-marks. These were identified from reference samples to be 3-indoleacetic acid, norharman, xanthurenic acid and Harman which all result from the degradation of tryptophan. Understanding gained from this experiment is that light causes photo-oxidation, resulting in enhanced degradation. As tryptophan is oxidised, it is separated from proteins, indicated by its derivatives on the TLC plate and ultimately fluorescence is reduced. These results are a 
useful stepping stone for developing an age determination method. Vital components in the fluorescence of aged finger-marks have been identified, which require further studies. This has incorporated variables including light conditions which have shown to impact fluorescence considerably. Cosmetic influences were also discussed and found to have no significant impact on the autofluorescence. Unfortunately, autofluorescence has not yet been quantified and therefore is not ready for implementation into a scientific method. Further studies must be conducted with more donors to assess reproducibility (only 6 were used) and allow for quantification and statistical analysis. In the time between the autofluorescence studies, research was conducted into the oxidation of finger-mark residue. Using fluorescence spectroscopy, an age-estimation model involving lipid and protein oxidation reactions was built. ${ }^{39}$ Relative quantities of oxidation products and the rate of production were measured. In addition to the research on the autofluorescence of tryptophan ${ }^{26,27}$ unsaturated lipids were found to oxidise in air to form products which form fluorescent products when reacting with proteins. The oxidation products (fat-protein emulsions) increase as the fluorescence from tryptophan decreases, enabling ratios to be calculated at different aging periods. Despite the significant finding, results indicated that these parameters may not be suitable for all fingerprints, as with $77 \%$ of the 22 female donor fingerprints, tryptophan was not present to a suitable fluorescent level. Furthermore, the effects of environmental conditions were not included despite being a large influential factorfurther work is required to assess this. Additionally, test samples of 22 female and 22 male donors are not sufficient to produce reliable aging results. However, results demonstrated significant findings, enabling the age of $55 \%$ of finger-marks (male) to be estimated up to 3 weeks old, possessing a relatively low uncertainty of 1.9 days. ${ }^{38}$ This displays further advancements than other research, as 3 weeks is a more realistic time-period in terms of live casework, than 240 hours.
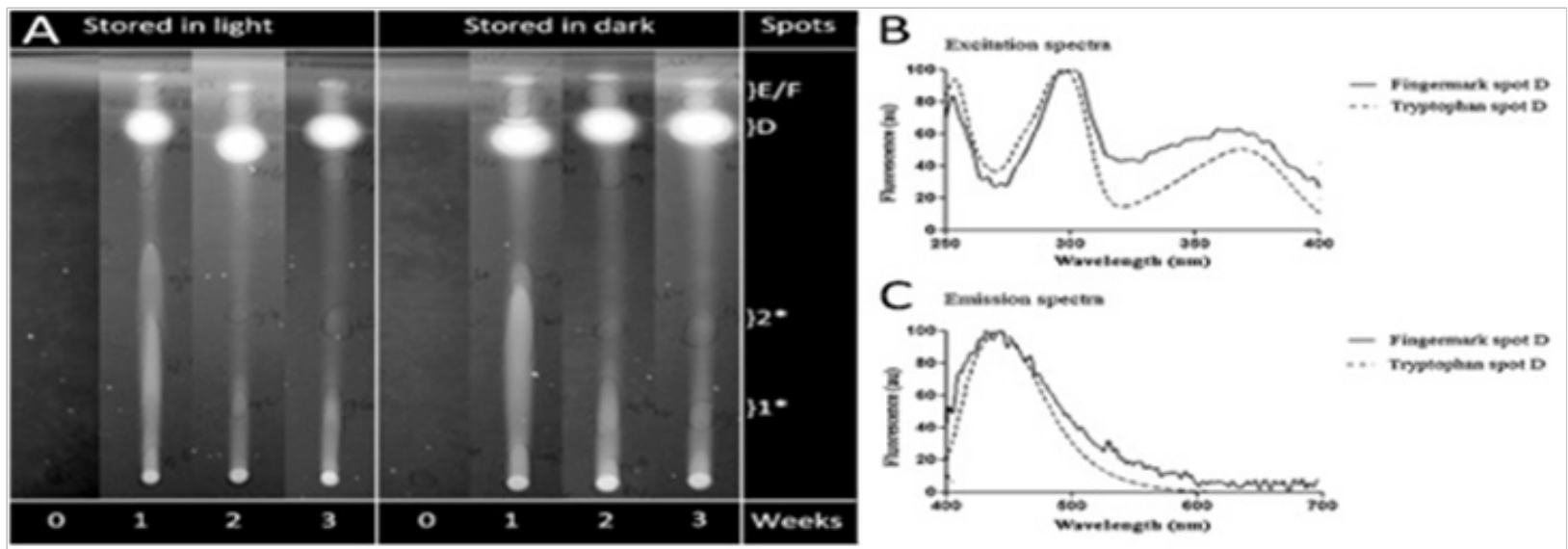

Figure 11 (A) TLC plates showing the aging of tryptophan at 0,1,2 and 3 weeks in both light and dark conditions. (B) Excitation spectra of finger-mark spot D and tryptophan spot D aged at 3 weeks. (C) Emission spectra of fluorescent spot D and tryptophan spot. ${ }^{27}$

\section{Raman spectroscopy}

Recent research used Raman Spectroscopy to estimate the age of finger-mark deposits. ${ }^{21}$ Through optical microscopy, two individual features of finger-mark residue were observed-oily and solid. Understanding residue composition, sebaceous secretions likely represent the oily regions, whilst solid particulates may be released from the epidermis resulting in a higher protein content. It is explained in the study that the solid particulates produce higher/more intense fluorescence compared to the oily regions. Displayed in Figure 12, spectral differences are visible between fresh and one-month old finger-mark residue.

To understand aging patterns, two-time experiments were conducted. One stored finger-mark samples in the dark for 4 weeks with regular examination using raman and infra-red spectroscopy, and another whereby samples were stored under ambient lighting with raman analysis conducted over 3 weeks. Observations of these showed that light conditions had influential impact on decay rates of specific raman bands representative of squalene, unsaturated fatty acids and carotenoids, whereas bands resulting from proteins demonstrated more stability. Table 7 shows a summary of the findings. ${ }^{21}$

The decay kinetics were interpreted by analysis of raman band changes with time. As a starting point for age estimation of finger- marks, there are several issues to be addressed. Larger data sets are required to determine reproducibility and accuracy of the study. By coupling spectroscopic analysis with other analytical techniques such as mass spectrometry, it gives the possibility of quantifying the compounds to establish by how much the compound has decayed in a certain time frame, which could then be analysed focusing on different influential factors. This would provide valuable data sets with potential to be utilised in testing to back date a recovered fingermark by quantifying the levels of a target compound present, applying knowledge of the effects of the deposition circumstances, decay kinetics may be identified, hopefully resulting in an age estimate. It is important to note that spectroscopic techniques such as Infrared, Raman and Fluorescence are non-destructive when used in non-contact mode, meaning the ridge detail persists for subsequent analysis, providing additional benefits.

\section{Chemical migration}

Research has discovered that chemical constituents in finger-mark residue gradually migrate over time. This movement provides potential to help determine the age. ${ }^{39}$ The National Institute of Standards and Technology identified the movement of biomolecules, such as fatty acids, from ridges down into the valleys at a consistent and predictable rate. ${ }^{39}$ The method used 'Time-of-Flight Secondary Ion Imaging Mass Spectrometry' (TOF-SIMS) an important analytical technique 
providing chemical and distributional (depth and lateral) information, using its high sensitivity, mass and spatial resolution. ${ }^{40}$ Fingerprints placed on silicon wafer samples were analysed to investigate the diffusivity of saturated fatty acid molecules. ${ }^{41}$ Focusing on palmitic acid (Figure 13), it was determined that 1 hour after deposition, the individual ridges were completely chemically visible, with the palmitic acid molecules located along the ridges, not contaminating the valleys. On analysis after 24 hours, it was apparent that migration of the molecules had begun and diffusion into the valleys was visible with the ridges becoming less obvious. 48 hours after initial deposition, the ridges were no longer chemically distinguishable from the valleys due to diffusion of the molecules (Figure 13). ${ }^{41}$ Mobility and diffusion rate was suggested to be dependent on molecular weight, demonstrated by larger molecule fragments displaying non-significant migration in the analysis time frame. The mobility rate is important in the dating older finger-marks. It gives an indication of which target molecules may still be present and not fully diffused due to the larger molecular weight. ${ }^{41}$ Muramoto and Sisco mentioned that this may introduce larger analysis errors due to the intensities of larger molecules being much lower than smaller ones. ${ }^{41}$ Should this technique be used in a court room, it opens to questioning on reliability of the results due to errors. The information gained was modelled using an error function with diffusivities that followed a power function when made into a plot against molecular weight. Diffusion of palmitic acid used the equation $\mathrm{x}=0.02 \mathrm{t}^{0.5}$ to show where the concentration was $50 \%$ of the initial value from initial deposition as a function of time (hours). ${ }^{31}$ The research is highly advantageous, potentially providing a technique which does not rely on chemical changes, rather molecular weights and diffusion models. ${ }^{29}$ these parameters have the advantage of being less affected by the multitude of influential factors. Molecular weights also do not vary on an inter or intrapersonal level, meaning that it could provide more standardised results. A limitation of this study, is the aging abilities of only up to four days, using finger-marks that have been deposited in an ideal situation..$^{41}$ In practice, this would not be beneficial as time frames would likely be larger and ridge detail could be present under any circumstances. Investigations must be conducted on more realistic test casework to explore and assess the reliability and success. Another limitation is the surface type, as it is possible that diffusivity may vary greatly depending on the material, texture and interfering contaminants. The article suggests that future work in this area will focus on analysis to over 240 hours, whilst investigating the impact of different non-porous surfaces.$^{41}$ However, it's common for them to be found on porous or semi-porous items. Additional work would benefit the criminal justice system as examination of marks may take longer than 10 days and so a reliable knowledge of how the marks may act over longer periods would be vital.

\section{GC/MS}

Gas Chromatography-Mass Spectrometry has been used to investigate aging of target lipid parameters in finger-mark residue, ${ }^{42}$ achieving a $60-100 \%$ test rate of age estimation. The research showed thoroughness in investigating influential factor effects on aging of the target lipids, evaluating factors including donor, substrate and enhancement techniques. The research concluded that the influential factor effects were greater than aging effects on the residue. Therefore, a high amount of difficulty is faced observing aging patterns, so is vital that effects of influential factors are known prior to aging methodology being produced and validated. The age of all test finger-marks stored under 'known' conditions were estimated correctly, unlike those from 'unknown' conditions. Substrate also displayed considerable effects, with squalene showing a lower value on glass (non-porous) substrate than on filters (porous), supporting Weyermann et al. ${ }^{13}$ A possible answer was suggested to be resultant from the residue collection method for analysis. Glass requires swabbing, whereas a filter can be fully immersed in the extraction solvents, potentially enabling more squalene to be recovered. To estimate the ages, six lipid target compounds were pre-processed with normalisation to the sum, followed by the square root to reduce variability. Multivariate models (principal component analysis and partial least square regression) were created from all six pre-processed variables. Squalene was used alone for the univariate models (likelihood ratios and exponential linear regression).The results confirmed influential factors had significant impact on the initial value of aging parameters and the aging process. This limitation is similar to other experiments ${ }^{21-31}$ with effects challenging to minimise. As a suggestion, for a successful aging model, requirements arise for a questioned and identified mark that is comparable in terms of substrate and enhancements to minimise variability. ${ }^{42}$ These parameters would display potential in identifying target compounds to analyse, process and compare changes with time. GC/MS is a sensitive and reliable technique for separation, analysis and identification of complex mixtures. ${ }^{13-43}$ The instrument is practical in the forensic field due to its widespread accessibility. Unfortunately, the results obtained have only distinguished between $<10$ days and $\geq 10$ days which in practise is not satisfactory. ${ }^{44}$ A questioned mark may be from a cold case which introduces a time of years, therefore pinpointing a more exact time will be significantly beneficial. Critically reviewing this method, it is destructive, requiring the residue to be removed from the substrate into the extraction solvent for analysis. This will ultimately destroy the fingerprint and ridge detail patterns, therefore evidential features for identification must be fully recorded prior to GC/MS analysis. A common feature of research conducted into the chemical components for aging parameters is the small sample sizes. The small samples give rise to larger potential errors, as reproducibility is minimised compared with a larger sample size which consider greater ranges of intra and intervariability. ${ }^{45}$

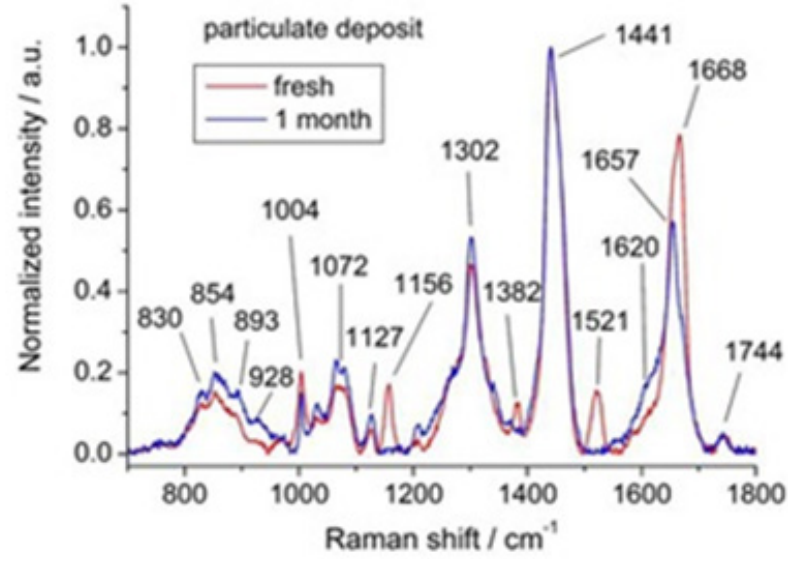

Figure 12 Raman spectra from particulate deposit of a freshly deposited finermark (red) and 1-month old finger-mark (blue). ${ }^{21}$

\section{$\mu-F T I R$}

In 2015, Fourier Transform Infrared Microscopy studied the composition and aging kinetics of finger-marks, from the initial deposition up to 1 month old. ${ }^{46}$ The study relied on visual examination 
of the spectra, along with chemometric processing due to the multivariate nature of the $\mu$-FTIR data. Initial analysis of composition allowed investigation of a selection of highest information value regions. These areas ranged from $1000-1850 \mathrm{~cm}^{-1}$, and $2700-3600 \mathrm{~cm}^{-}$ ${ }^{1}$, focussing on peaks made by eccrine and sebaceous secretions. The results displayed that eccrine disappeared rapidly over time, whilst sebaceous decreased without disappearing. These features were demonstrated by a decrease in the intensity of all vibrational bands from the aged spectra. Of the two substrates investigated (aluminium foil and glass), along with environmental conditions (light and dark), analysis indicated that finger-marks stored in the light could be grouped by age regardless of substrate, whilst those stored in the dark showed more erroneous results displaying dependency on substrate with age easier to distinguish on glass. Overall, this study showed significant findings supported in other research with sebaceous secretions persisting longer than eccrine. $\mu$-FTIR provides a successful technique for observing the aging of finger-marks that is quick, non-destructive and suitable for the policing world considering relatively low costing, in contrast to GC/MS, possessing a long sample preparation time with a destructive technique. On the other hand, drawbacks and limitations to this study are minimal donor variability and quantity of marks tested. Sufficient comparison between donors is not achieved, considering intervariability. Additionally, the surface type limits analysis into effects of different substrates, with only two, non-porous surfaces involved. It appears that the foil samples aged up to 34 days, whilst glass only to 9 . This does not allow for direct comparison so cannot provide accurate information on aging kinetics on different surfaces. FTIR is most suitable on non-porous surfaces, limiting the success of the technique in a live casework environment.

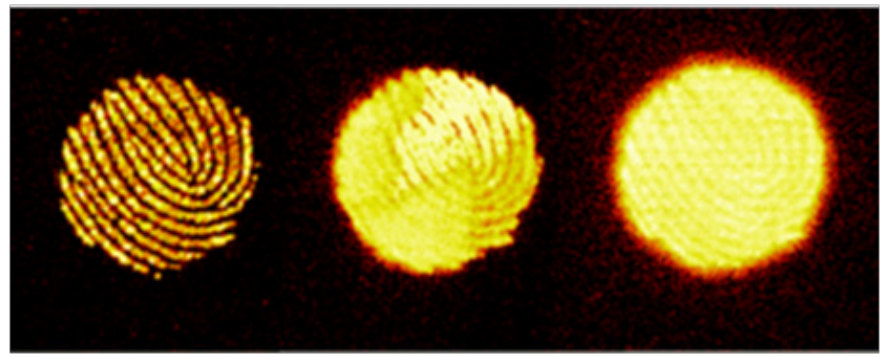

Figure 13 TOF-SIMS ion images showing the distribution of palmitic acid at $\mathrm{t}=1, \mathrm{t}=24$ and $\mathrm{t}=48$ hours after deposition. ${ }^{31}$

Table 7 A summary of findings in a raman spectroscopy initial study into the aging of finger-marks, displaying the similarities and differences for various compounds when stored under light or dark conditions ${ }^{21}$

\begin{tabular}{lllll}
\hline $\begin{array}{l}\text { Compound } \\
\text { observation }\end{array}$ & Carotenoid & Squalene & $\begin{array}{l}\text { Unsaturated fatty } \\
\text { acids }\end{array}$ & Proteins \\
\hline & & & $830,854,1004,1032,1174,1208,1556$, \\
Raman & $1521,1157,1007$ & 1668,1382 & 1657 & $1605-1620$ (aromatic side chains) \\
Shift/cm-1 & & & & $1600-1700$ (amide I) \\
& & & $1230-1300$ (amide III)
\end{tabular}

$\begin{array}{ll}\text { Decay Rate: } & \text { Rapid decline-likely due to } \\ \text { Dark } & \begin{array}{l}\text { oxidation } \\ \text { conditions }\end{array}\end{array}$

\section{Slower than carotenoid}

bands.

$1668 \mathrm{~cm}-1$ peak still observed after $700 \mathrm{~h}$.

Band shows slight increase and shifts to $1672 \mathrm{~cm}-1$ before returning to $1668 \mathrm{~cm}-1$

More rapid decay in ambient light. $1668 \mathrm{~cm}-1$ peak disappeared into background noise after 140 hours.

Decomposition occurred in a matter of days.
Stable over the first 12 days. Observed kinetic reaction is slower than squalene.

Protein raman bands still visible after 4 weeks of aging. Over time, relative protein contribution in $1600-1700 \mathrm{~cm}-1$ band increases unlike others which degrade faster. Oily areas aged over 100 hours showed a slight increase in relative raman intensity at

$1630 \mathrm{~cm}-1$ regardless of light.

Peak level decreased rapidly, although the observed kinetic reactions are slower than squalene.
Oily areas aged over 100 hours showed a slight increase in relative raman intensity at $1630 \mathrm{~cm}-1$ regardless of light. $\begin{array}{ll}\text { Light } & \text { initially observed for solid } \\ \text { Conticulates. Observation of }\end{array}$

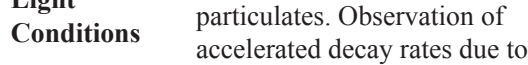
photo-bleaching.

\section{Comparison of methods utilising chemical characteristics}

(Table 8)

\section{Comparison}

Table 7 provides a critical summary to identify the qualities of different methods used to offer a way to potentially date a finger-mark (Table 9).

\section{Additional research}

Without solid conclusions and answers to finger-mark dating, additional investigation is necessary. As mentioned throughout this article, influential factors play a vital role in finger-mark composition, from initial deposition to the aged residue. Despite studies considering a select number of influential characteristics, it is difficult to include all and control or vary each one as necessary. Unfortunately, until the effects have been thoroughly investigated, a concrete aging model cannot be produced. When aging is questioned, it's likely after chemical enhancement and identification. Enhancement processes will introduce different constituents into the residue, meaning additional factors to investigate. Studies should be conducted into the alterations that chemical procedures may make to the finger-mark, physically and chemically. This includes lifting a finger-mark. Some studies into aging have included lifting but may be inaccurate. A mark may be modified with each lift for subsequent aging analysis and therefore may inaccurately represent the change from initial deposition. This leaves room for research into the effects of lifting marks over time. It must be appreciated however, that if several depositions have been made to study the aging by lifting a different one each time and this may also be inaccurate considering the intravariability of marks. Furthermore, studies show a common result of lipids possessing more 
stability over time and therefore demonstrating more potential as aging components, consequently future research should base aging models on lipid change over time. Ratios between target compounds have demonstrated success, enabling influential factor effects to be minimised. The ratio of Squalene: Cholesterol has seemed promising in research but requires additional work for reproducible data. Most

Table $8 \mathrm{~A}$ table to show comparison with the advantages and disadvantages of each of the chemical characteristic techniques used in attempt to estimate the age of a finger-mark

\begin{tabular}{|c|c|c|}
\hline Technique & Advantages & Disadvantages \\
\hline $\begin{array}{l}\text { TLC \& } \\
\text { Fluorescence }\end{array}$ & $\begin{array}{l}\text {-Stronger fluorescence on older marks } \\
\text {-The age was estimated with } 1.9 \text { days accuracy } \\
\text {-A target compound was identified for analysis } \\
\text {-Storage conditions were considered }\end{array}$ & $\begin{array}{l}\text {-Limited donor numbers, with donor variability exhibiting } \\
\text { significant effects on the results } \\
\text {-Some finger-marks did not display fluorescence } \\
\text {-Only a 3-week aging period was used. IT would be more } \\
\text { beneficial to be considerably longer } \\
\text {-Quantification was not obtained } \\
\text {-Destructive }\end{array}$ \\
\hline $\begin{array}{l}\text { Fluorescence } \\
\text { Spectroscopy }\end{array}$ & $\begin{array}{l}\text {-Ratios between target compounds were investigated (fat- } \\
\text { protein emulsions and tryptophan) } \\
\text {-The age was estimated with } 1.9 \text { days accuracy } \\
\text {-Non-destructive }\end{array}$ & $\begin{array}{l}\text {-The ratio between the target compounds is not always suitable } \\
\text {-Female donors lack such high levels of fluorescent tryptophan, } \\
\text { making analysis difficult } \\
\text {-No environmental conditions considered during testing }\end{array}$ \\
\hline $\begin{array}{l}\text { Raman } \\
\text { Spectroscopy }\end{array}$ & $\begin{array}{l}\text {-Foreign components can also be analysed for degradation } \\
\text { over time } \\
\text {-Light and dark conditions considered } \\
\text {-Non-destructive }\end{array}$ & $\begin{array}{l}\text {-Limited donor numbers/variability } \\
\text {-Aging periods not realistic } \\
\text {-No quantification obtained }\end{array}$ \\
\hline TOF-SIMS & $\begin{array}{l}\text {-A target compound was identified for analysis } \\
\text {-A visual change observed in the finger-mark over time } \\
\text {-Molecular weight dependent, therefore less affected by } \\
\text { influential factors }\end{array}$ & $\begin{array}{l}\text {-Large analysis errors obtained } \\
\text {-Aging period not realistic ( } 4 \text { days) } \\
\text {-Limited substrate type }\end{array}$ \\
\hline GC/MS & $\begin{array}{l}\text {-Target lipid parameters utilised } \\
\text {-Thorough investigation for influential factors } \\
\text {-Sensitive and reliable technique for small amounts of residue }\end{array}$ & $\begin{array}{l}\text {-Conclusion reached that influential factors have a larger effect } \\
\text { than aging on the change over time } \\
\text {-Difficulty shown to age marks when storage conditions were } \\
\text { unknown } \\
\text {-Aging only distinguished to be }<10 \text { or } \geq 10 \text { days old } \\
\text {-Reproducibility issues } \\
\text {-Destructive }\end{array}$ \\
\hline$\mu$-FTIR & $\begin{array}{l}\text {-Up to } 1 \text {-month aging period on foil substrate } \\
\text {-Non-destructive }\end{array}$ & $\begin{array}{l}\text {-Limited substrate testing } \\
\text {-Only non-porous items suitable } \\
\text {-Limited donor variability }\end{array}$ \\
\hline
\end{tabular}

\begin{tabular}{|c|c|c|}
\hline Technique & Advantages & Disadvantages \\
\hline $\begin{array}{l}\text { TLC \& } \\
\text { Fluorescence }\end{array}$ & $\begin{array}{l}\text {-Stronger fluorescence on older marks } \\
\text {-The age was estimated with } 1.9 \text { days accuracy } \\
\text {-A target compound was identified for analysis } \\
\text {-Storage conditions were considered }\end{array}$ & $\begin{array}{l}\text {-Limited donor numbers, with donor variability exhibiting } \\
\text { significant effects on the results } \\
\text {-Some finger-marks did not display fluorescence } \\
\text {-Only a 3-week aging period was used. IT would be more } \\
\text { beneficial to be considerably longer } \\
\text {-Quantification was not obtained } \\
\text {-Destructive }\end{array}$ \\
\hline $\begin{array}{l}\text { Fluorescence } \\
\text { Spectroscopy }\end{array}$ & $\begin{array}{l}\text {-Ratios between target compounds were investigated (fat- } \\
\text { protein emulsions and tryptophan) } \\
\text {-The age was estimated with } 1.9 \text { days accuracy } \\
\text {-Non-destructive }\end{array}$ & $\begin{array}{l}\text {-The ratio between the target compounds is not always suitable } \\
\text {-Female donors lack such high levels of fluorescent tryptophan, } \\
\text { making analysis difficult } \\
\text {-No environmental conditions considered during testing }\end{array}$ \\
\hline $\begin{array}{l}\text { Raman } \\
\text { Spectroscopy }\end{array}$ & $\begin{array}{l}\text {-Foreign components can also be analysed for degradation } \\
\text { over time } \\
\text {-Light and dark conditions considered } \\
\text {-Non-destructive }\end{array}$ & $\begin{array}{l}\text {-Limited donor numbers/variability } \\
\text {-Aging periods not realistic } \\
\text {-No quantification obtained }\end{array}$ \\
\hline TOF-SIMS & $\begin{array}{l}\text {-A target compound was identified for analysis } \\
\text {-A visual change observed in the finger-mark over time } \\
\text {-Molecular weight dependent, therefore less affected by } \\
\text { influential factors }\end{array}$ & $\begin{array}{l}\text {-Large analysis errors obtained } \\
\text {-Aging period not realistic ( } 4 \text { days) } \\
\text {-Limited substrate type }\end{array}$ \\
\hline GC/MS & $\begin{array}{l}\text {-Target lipid parameters utilised } \\
\text {-Thorough investigation for influential factors } \\
\text {-Sensitive and reliable technique for small amounts of residue }\end{array}$ & $\begin{array}{l}\text {-Conclusion reached that influential factors have a larger effect } \\
\text { than aging on the change over time } \\
\text {-Difficulty shown to age marks when storage conditions were } \\
\text { unknown } \\
\text {-Aging only distinguished to be }<10 \text { or } \geq 10 \text { days old } \\
\text {-Reproducibility issues } \\
\text {-Destructive }\end{array}$ \\
\hline$\mu$-FTIR & $\begin{array}{l}\text {-Up to } 1 \text {-month aging period on foil substrate } \\
\text {-Non-destructive }\end{array}$ & $\begin{array}{l}\text {-Limited substrate testing } \\
\text {-Only non-porous items suitable } \\
\text {-Limited donor variability }\end{array}$ \\
\hline
\end{tabular}

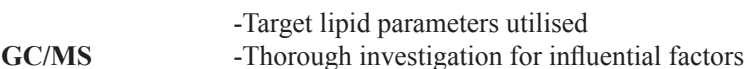

-Sensitive and reliable technique for small amounts of residue studies possessed relatively small sample sizes which again should be advanced in research to include more donors and finger-marks to evaluate the reproducibility. Most research has been undertaken in laboratories, meaning there are no techniques yet capable of crime scene use. Evidentially, more research under realistic conditions should be conducted.

Table 9 A table to show a comparison summary of all proposed techniques for the aging of a finger-mark

\begin{tabular}{|c|c|c|c|c|c|c|}
\hline Technique & $\begin{array}{l}\text { Destruc- } \\
\text { tive }\end{array}$ & $\begin{array}{l}\text { Analysis } \\
\text { Time }\end{array}$ & Reproducibility & $\begin{array}{l}\text { Can it be } \\
\text { quantified? }\end{array}$ & Advantages & Disadvantages \\
\hline $\begin{array}{l}\text { Microscopic/ } \\
\text { Macroscopic } \\
\text { Analysis }\end{array}$ & No & Quick & $\begin{array}{l}\text { Trends observed but varies } \\
\text { from person to person }\end{array}$ & Yes & $\begin{array}{l}\text { Less contamination } \\
\text { than chemical processes }\end{array}$ & $\begin{array}{l}\text { Difficult to understand what FM } \\
\text { looked like at deposition }\end{array}$ \\
\hline $\begin{array}{l}\text { Electrostatic } \\
\text { Charge }\end{array}$ & No & Quick & $\begin{array}{l}\text { Exponential decay curve } \\
\text { obtained suggesting } \\
\text { reproducibility }\end{array}$ & Yes & $\begin{array}{l}\text { High sensitivity and } \\
\text { low noise levels }\end{array}$ & $\begin{array}{l}\text { Rate of decay is highly substrate } \\
\text { dependent. Not suitable for very } \\
\text { old finger-marks }\end{array}$ \\
\hline TLC & Yes & Quick & $\begin{array}{l}\text { Donor variability is } \\
\text { significant }\end{array}$ & No & $\begin{array}{l}\text { Simple to use and } \\
\text { inexpensive }\end{array}$ & $\begin{array}{l}\text { Length of separation limited, some } \\
\text { compounds may not separate }\end{array}$ \\
\hline $\begin{array}{l}\text { Fluorescence } \\
\text { Spectroscopy }\end{array}$ & No & Quick & $\begin{array}{l}\text { Donor variability is } \\
\text { significant, ratios increase } \\
\text { reproducibility }\end{array}$ & Yes & $\begin{array}{l}\text { High sensitivity \& } \\
\text { simple to use. Little to } \\
\text { no prep required }\end{array}$ & Not all compounds fluorescence \\
\hline $\begin{array}{l}\text { Raman } \\
\text { Spectroscopy }\end{array}$ & No & Quick & $\begin{array}{l}\text { Donor variability is } \\
\text { significant }\end{array}$ & No & $\begin{array}{l}\text { Highly specific with no } \\
\text { sample prep }\end{array}$ & $\begin{array}{l}\text { Background fluorescence could } \\
\text { disguise peaks }\end{array}$ \\
\hline TOF-SIMS & Yes & Slow & $\begin{array}{l}\text { Large errors mean results } \\
\text { are difficult to reproduce }\end{array}$ & $\begin{array}{l}\text { Semi- } \\
\text { quantitative }\end{array}$ & Visual change visible & $\begin{array}{l}\text { Long \& complex analysis for } \\
\text { quantitative results }\end{array}$ \\
\hline GC/MS & Yes & Slow & $\begin{array}{l}\text { Analysis not reproducible } \\
\text { with a small sample size }\end{array}$ & Yes & $\begin{array}{l}\text { Sensitive \& reliable. } \\
\text { Couples ident with } \\
\text { quant }\end{array}$ & Long analysis time \\
\hline$\mu$-FTIR & No & Quick & Reproducibility not tested & Yes & $\begin{array}{l}\text { Minimal sample prep } \\
\text { required }\end{array}$ & $\begin{array}{l}\text { Only suitable for non-porous } \\
\text { exhibits }\end{array}$ \\
\hline
\end{tabular}




\section{Conclusion}

Analysis conducted into the aging of finger-marks should be non-destructive, relatively fast and cheap, with the capability of laboratory and scene use. An aging model must be thoroughly analysed and evaluated to provide qualitative and quantitative results that can be adapted on a case-to-case or even mark-to-mark basis. Case related experiments should be conducted to help provide intelligence from reconstructed conditions, but unfortunately due to the large variations with each person and their residue, production of a 'one size fits all' general aging model would be rare. This paper has reviewed investigative, physical and chemical characteristics as aging parameters in an aim to find the best technique to provide ages of finger-marks. The main struggle with all techniques is the influential factors which introduce extremely large variations. Whilst investigative information only progresses a case so far, much of the outcome relies on forensic evidence in the form of physical or chemical characteristics. Without knowing the visual properties of the ridge detail (i.e. minutiae/pore shape) at initial deposition, is it practical to then observe how it has changed with time? This leads on to the chemical characteristics perhaps providing the most reliable methods. By investigating a ratio between two target compounds, it may provide the most successful aging parameters for subsequent analysis and comparison. A spectroscopic technique to identify components, coupled with an analytical instrument, e.g. mass spectrometer, may provide accurate quantification. Obtaining reproducible data is vital in forensic casework, enabling validation. The data provides a starting point for an aging curve, but with lack of consistency large error bars would be introduced and the quality of work and expert professionalism may be questioned. Ultimately, the aging of finger-marks is not something that can be assessed based on experience, as demonstrated by case studies, but is a subject whereby finger-marks must undergo accurate analytical techniques prior to being employed as evidence in a court room.

\section{Acknowledgments}

None.

\section{Conflicts of interest}

The author declares that there is no conflicts of interest.

\section{References}

1. The Open University. Forensic Science and Fingerprints.

2. Cadd S Islam, Manson PM, Bleay S. Fingerprint composition and aging: A literature review. Science \& Justice. 2015;55(4):219-238.

3. Weyermann C, Ribaux O. Situating forensic traces in time. Science \& Justice. 2012;52(2): 68-75.

4. United Kingdom Accreditation Service. Forensic Science.

5. Girod A, Ramotowski R, Weyermann C. Composition of fingermark residue: A qualitative and quantitative review. Forensic Science International. 2012;223(1-3):10-24.

6. Jackson A, Jackson J. Forensic Science. $3^{\text {rd }}$ Edition. 2011.

7. Galton F. Finger Prints. Macmillan and Co. 1982.

8. Edgar Hoover J. Fingerprint Anatomy.

9. The History of Fingerprints. 2017.

10. Forensic Handbook. Locard's exchange principle.
11. Jackson A, Jackson J. Forensic Science. $3^{\text {rd }}$ Edition. Prentice Hall. 2011.

12. Kent T. Water content of latent fingerprints-Dispelling the myth. Forensic Science International. 2016;226:134-138.

13. Weyermann $\mathrm{C}$, Roux $\mathrm{C}$, Champod C. Initial results on the composition of fingerprints and its evolution as a function of time by $\mathrm{GC} / \mathrm{MS}$ analysis. Journal of Forensic Sciences. 2011;56(1):102-108.

14. Vestigial Evolution. Arrector Pili.

15. Croxton R, Baron M, Butler D, et al. Variation in amino acid and lipid composition of latent fingerprints. Forensic Science International. 2010;199(1-3):93-102.

16. The Editors of Encyclopaedia Brittanica. Sweat Gland. 2018.

17. Picardo M, Ottaviani M, Camera E, et al. Sebaceous gland lipids. Dermato Endocrinology. 2009;1(2)68-71.

18. Champod C, Lennard, C, Margot P, et al. Age Estimation of Latent Marks. Fingerprints and Other Skin Ridge Impressions. $1^{\text {st }}$ Edition. CRC Boca Raton 2005.

19. The Home Office Centre for Applied Science and Technology. Fingermark Visualisation Manual. $1^{\text {st }}$ Edition. Stationary Office. 2014.

20. Daluz H. Fundamentals of Fingerprint Analysis. $1^{\text {st }}$ Edition. CRC Press. 2014.

21. Anderson PO, Lejon C, Mikaelsson T, et al. Towards Fingermark Dating: A Raman Spectroscopy Proof-of-Concept Study. Chemistry Open. 2017;6(6):706-709.

22. Olsen R. Chemical Dating Techniques for Latent Fingerprints: A preliminary report. Identification News. 1987.

23. Sodhi GS, Kaur J. Physical Developer method for detection of latent fingerprints: A review. Egyptian Journal of Forensic Sciences. 2015;6(2):44-47.

24. BVDA. Physical Developer.

25. Bunter $\mathrm{S}$. How long can an identifiable fingerprint persist on an exterior surface? CSEye. 2014.

26. SQA Forensic Science. Report on: Forensic Science. Information: Third Level Detail.

27. Popa G, Potorac R, Preda N. Methods for fingerprints age determination. Romanian Journal of Legal Medicine. 2010;18(2):149-154.

28. Verma M, Agarwal S. Fingerprint based male-female classification. Proceedings of the International Workshop on Computational Intelligence in Security for Information Systems CISIS'08. Advances in Soft Computing. 2009;53:251-257.

29. Kralik M, Novotny V. Epidermal Ridge Breadth: An indicator of age and sex in paleodermatoglyphics. Variability and Evolution. 2003;11:5-30.

30. Bansal R, Seghal P, Bedhi P. Minutiae Extraction from Fingerprint Images- a Review. International Journal of Computer Science Issues. 2011;8(5):74-85.

31. Watson P, Prance R, Beardsmore-Rust S, et al. Imaging Electrostatic Fingerprints with Implications for a Forensic Timeline. Forensic Science International. 2011;209(1-3):e41-e45.

32. Holyst B. Criminal Assessment of the Age of Fingerprints. Arch Kriminol. 1987;179(3-4):94-103.

33. Banuik K. Determination of Age of Fingerprints. Forensic Science International. 1990;46(1-2):133-137.

34. Merkel R. Latent Fingerprint Age Estimation. New Solutions for an Old Challenge. Chances and Limitations of Optical, Non-invasive 
Acquisition and Digital Processing Techniques for the Age Estimation of Latent Fingerprints. Logos Verlag Berlin GmbH. 2014;14-15.

35. Girod A, Spyratou A, Holmes D, et al. Aging of Target Lipid Parameters in Fingermark Residue Using GC/MS: Effects of Influence Factors and Perspectives for Dating Purposes. Science \& Justice. 2016;56(3):165-180.

36. Gas Chromatography/Mass Spectrometry (GC/MS).

37. Sauer M, Hofkens J, Enderlein J. Basic Principles of Fluorescence Spectroscopy. Handbook of Fluorescence Spectroscopy and Imaging: From Single Molecules to Ensembles. 2011.

38. Van Dam A, Schwarz J, de Vos J, et al. Oxidation Monitoring by Fluorescence Spectroscopy Reveals the Age of Fingermarks. Angewandte Chemie. 2014;53(24):6272-6275.

39. Lambrechts SAG, Van Dam A, de Vos J, et al. On the autofluorescence of fingermarks. Forensic Science International. 2012;222(1-3):89-93.

40. Lambrechts SAG, Van Dam A, Aalders MCG, et al. On the autofluorescence of aged fingermarks. Forensic Science International. 2016;258:19-25.
41. Locard's Lab. Determining the age of a fingerprint: Is it possible?

42. The National Institute of Standards and Technology. Who, What, WHEN: Determining the age of fingerprints. 2015.

43. Sodhi, R. Time-of-flight secondary ion mass spectrometry (TOFSIMS): - Versatility in chemical and imaging surface analysis. Analyst. 2004;129(6):483-487.

44. Muramoto S, Sisco E. Strategies for Potential Age Dating of Fingerprints Through the Diffusion of Sebum Molecules on a Nano-porous Surface Analysed Using Time-of-Flight Secondary Ion Mass Spectrometry. Analytical Chemistry. 2015;87(16):8035-8038.

45. Wertheim K. Fingerprint age determination: Is there any hope? Journal of Forensic Identification. 2003;53(1):42-49.

46. Girod A, Xiao L, Reedy B, et al. Fingermark Initial Composition and Aging Using Fourier Transform Infrared Microscopy ( $\mu-$ FTIR). Forensic Science International. 2015;254:185-196. 